\title{
Nutritional and immunological factors in breast milk: a role in the intergenerational transmission from maternal psychopathology to child development
}

Maria Grazia Di Benedetto ${ }^{1 *}$, Chiara Bottanelli $^{1 *}$, Annamaria Cattaneo ${ }^{1,2}$, Carmine Maria Pariante ${ }^{1,}$ ${ }^{2}$, Alessandra Borsini ${ }^{1 * *}$

\footnotetext{
${ }^{1}$ Section of Stress, Psychiatry and Immunology \& Perinatal Psychiatry, King's College London, Institute of Psychiatry, Psychology \& Neuroscience, Department of Psychological Medicine, London, UK.

${ }^{2}$ Biological Psychiatry Unit, IRCCS Fatebenefratelli S. Giovanni di Dio, Brescia, Italy.

*these authors contributed equally to this work

**corresponding author: Alessandra Borsini alessandra.borsini@kcl.ac.uk
}

Maria Grazia Di Benedetto: maria_grazia.di_benedetto@kcl.ac.uk

Chiara Bottanelli: chiara.bottanelli@kcl.ac.uk

Annamaria Cattaneo: annamaria.cattaneo@kcl.ac.uk

Carmine M. Pariante: carmine.pariante@kcl.ac.uk

Alessandra Borsini: alessandra.borsini@kcl.ac.uk 


\begin{abstract}
Perinatal psychopathologies affect more than $25 \%$ of women during and after their gestational period. These psychiatric disorders determine important biological variations in their organisms, affecting many different physiological and metabolic pathways. Of relevance, any of these changes occurring in the mother can alter the normal composition of breast milk, particularly the concentration of nutritional and inflammatory components, which play a role in child brain functioning and development. Indeed, there is evidence showing that changes in milk composition can contribute to cognitive impairments and alterations in mental abilities in children. This review aims to shed light on the unique intergenerational role played by breast milk composition, from maternal psychopathologies to child development.
\end{abstract}

Key words: breast milk composition; perinatal depression; perinatal anxiety; child neurodevelopment; child behavior. 


\section{Introduction}

It has been suggested for some time that stress exposure during the perinatal period may affect the quality of milk (Kawano et al., 2009), which is fundamental not only to sustain child growth and development (Butte and King, 2005; Hair et al., 2013), but also to support the normal brain functioning of the child (Horta et al., 2018). Indeed, maternal milk is an important physiological fluid for nutrient transfer and immune signalling, which potentially shapes infant growth at a cognitive, behavioral and motor level. Therefore, any changes in maternal psychopathology that could severely impact milk composition can also in turn predispose the child to developmental difficulties (Figure 1).

Although many psychological and physiological changes are normal during the perinatal period, if exacerbated, they can predispose women to the development of clinically significant psychiatric conditions, particularly mood and anxiety disorders (Bobo and Yawn, 2014; Paschetta et al., 2014). Perinatal depression is a common disorder that affects women during and after pregnancy (Evans et al., 2001; Thompson and Ajayi, 2016). This disorder is characterized by a wide spectrum of symptoms, ranging from apathy, appetite and sleep disruption, to cognitive problems and suicidal thoughts, and it can occur at different levels of severity ranging from mild to severe (Kazemi, 2016; Pearlstein et al., 2009). It is usually classified as a major depressive disorder (MDD) with a postpartum onset, within one month after delivery. However, more recently The Diagnostic and Statistical Manual of Mental Disorders-V (DMS-V) extended the previous definition of postpartum depression to perinatal depression, which includes also antenatal depression, since this mental illness may start during pregnancy or beyond the first month postpartum (American Psychiatric Association, 2013; Biaggi et al., 2016; Gavin et al., 2005). It is well known that both psychological and psychosocial factors can play a crucial role in the onset of the depressive psychopathology, therefore the perinatal period can be a window of susceptibility. 
Similarly to depression, also perinatal anxiety and stress present a prevalence as high as 10$25 \%$ in pregnant women (Fairbrother et al., 2016; Loomans et al., 2012), even though less attention has been given to these perinatal psychopathologies (Reck et al., 2008). Of note, mothers with depression have reported co-morbid symptoms of both anxiety and stress (Miller et al., 2006), therefore suggesting the presence of common underlying mechanisms among these conditions. From this perspective, evidence coming from both human and animal models implicate hormonal dysregulation, abnormalities in hypothalamic-pituitary-adrenal axis activity, and the contributions of genetics and epigenetics as playing key roles in the development of those perinatal psychopathologies (Meltzer-brody, 2011). Although few mechanisms have been identified, it is still not clear how psychological and biological alterations present in the mother can be transmitted intergenerationally and ultimately affect child development.

Indeed, a wide array of biological, social and environmental factors have acquired a lot of attention as potential links explaining the association between maternal psychopathologies and child development (Sawyer et al., 2018). Great emphasis has been given to biological changes occurring during the gestational period, with particular focus on those associated with perinatal stress. Indeed, experience of excessive stress during pregnancy can expose the foetus to high level of cortisol (Reynolds, 2013), and induce epigenetic changes of genes involved in the stress (Cecil et al., 2015; Mulligan et al., 2012), and immune response (Cattaneo et al., 2018; Vaiserman, 2015), ultimately contributing to a long term impact on infant development (Bronson and Bale, 2015). Alternatively, other evidence coming from studies investigating the role of postpartum maternal care on child development has proposed maladaptive parenting as a causative determinant for the association between perinatal psychopathologies and adverse child outcomes (Silberg and Rutter, 2002). In particular, maternal disengagement and withdrawal behaviors, which are common traits in mental 
psychiatric disorders, can negatively impact parenting quality (Field, 2011), and cause deleterious consequences on infant cognitive abilities and emotional responsiveness (Murray et al., 2015; Stein et al., 2014). Despite the widely documented involvement of the mentioned mechanisms, these alone still fail in providing a comprehensive understanding of the heterogeneity and complexity of the link between maternal psychopathologies and child development. Other mechanisms are likely to contribute significantly in an interlinked pattern of environmental and molecular factors.

In the recent years increasing attention has been given to the role of breast milk composition, which offers a unique nutritional support to the child development. Indeed, the lactation period is characterized by a continuous demand on mothers to provide all necessary nutrients to the infant. Therefore, due to the multiple biological changes that characterize perinatal mental disorders, including changes in hormonal levels, immune response, vitamins and nutrients, a compromised maternal health might lead to insufficient or abnormal amounts of nutrients and other biological factors in breast milk, ultimately affecting child development. In this review, we will start by summarising the main components of milk, including nutritional and immunological factors, and their importance for child development. We will then examine all studies that have looked at changes in breast milk composition in mothers with mental disorders, and the potential association with child development. We will conclude by discussing the putative role of breastmilk in the intergenerational transmission of mental health problems.

\section{The importance of breast milk}

\subsection{Lactation stages}

To best adapt to the child's metabolic and nutritional necessities, breast milk composition changes constantly throughout the entire lactation period. It is commonly classified into: colostrum, transitional milk and mature milk, with reference to a gradual adjustment process (Ballard and 
Morrow, 2013). Colostrum is the secretion produced during the first few days after delivery, containing a wide array of proteins and growth factors, and it is rich in immunological components, such as immunoglobulins and leukocytes, which play a major role in building up the immune system in newborns (Gephart and Weller, 2014; Neville et al., 1988; Neville and Morton, 2018; Pang and Hartmann, 2007; Pribylova et al., 2012). Transitional milk is produced after colostrum and lasts for approximately two weeks. The content of transitional milk includes high levels of fat, lactose and water-soluble vitamins, and it contains a higher abundance of calories than colostrum (Gidrewicz and Fenton, 2014). Finally, mature milk is produced from about day 15. It consists of $90 \%$ water and $10 \%$ of carbohydrates, proteins and fats, and therefore results in a more watery milk (Jenness, 1979).

\subsection{Components of human milk}

As it changes throughout the different periods of lactation, finely attuning to every requirement of the new baby, breast milk constitutes a comprehensive source of macronutrients, micronutrients as well as bioactive factors, which are essential for the growth of the child (Picciano, 2001). The volume and composition of human milk varies between individuals, and even in the same woman it can be altered by her nutritional status (Gidrewicz and Fenton, 2014; Pauline M. Emmett et al., 1997).

\section{Lipids}

The total lipid content, milk's main source of energy, is extremely variable depending on timing or physical condition of the mother, showing a gradual increase from the beginning of feeding, defined as foremilk, to the end of a feed, known as hindmilk (Picciano, 2001; Saarela et al., 2005). Almost all of the lipids in breast milk are triglyceride with polyunsaturated fatty acids (PUFAs), which are essential for the nutritional and developmental needs of the child (Picciano, 
2001). In particular, long-chain PUFAs (L-PUFAs) arachidonic acid (ARA) and docosahexaenoic acid (DHA), should be present in a 2:1 ratio in colostrum to best benefit the infant from the very first days after delivery, however their concentration varies widely in relation to maternal diet (Kelishadi et al., 2012). Indeed, L-PUFAs are not produced endogenously and can be introduced via a specific diet rich in fish and nuts (Birch et al., 2005; Hadley et al., 2016; Makrides et al., 1994).

\section{Vitamins, ions and metals}

Along with macronutrients, human milk provides necessary micronutrients, such as vitamins, which are essential bioregulators for metabolic activities. The concentration of some water-soluble vitamins, such as thiamin, vitamin B-6 and biotin, increases during the lactation period, while the riboflavin content remains constant. Vitamins $\mathrm{A}$ and $\mathrm{E}$ are present in high concentrations in colostrum compared to mature milk, while vitamins $\mathrm{D}$ and $\mathrm{K}$ remain in low quantity in human milk (Coryell et al., 1945; Dror and Allen, 2018). Maternal diet seems to notably influence the vitamin profile in breast milk, resulting, in some cases, in the necessity of dietary supplementation for the mother during the lactation period (Valentine and Wagner, 2013). In contrast, other micronutrients, such as ions and mineral salts, show a constant bioavailability during the course of lactation, with the exception of zinc, copper and iron, which are present in high concentration immediately after childbirth, but decrease in the following months, and seem to be less influenced by maternal diet (Dror and Allen, 2018).

\section{Immune components}

Alongside its nutritional role, breast milk contributes also to the development of the infant's immune system. Indeed, it contains a plethora of immunological factors, which includes immune cells, such as macrophages, neutrophils, $\mathrm{T}$ cells, stem cells and lymphocytes, proteins, like the lysoenzyme, an aspecific antimicrobial factor, different cytokines and many immunoglobulins (Ig): 
IgM, IgG, secretory IgG and especially secretory $\operatorname{IgA}(\mathrm{sIgA})$ (Palmeira and Carneiro-Sampaio, 2016; Prentice et al., 1987). During pregnancy, the mother transmits her antibodies to the foetus through the placenta; then, in the postnatal period, the newborn receives these antibodies from breast milk, establishing a defense mechanism for the first months of life (Berg et al., 2014; Hanson and Söderström, 1981).

\section{Hormones}

In addition to nutrients and immune components, human milk contains a substantial number of hormones, that act on many different physiological and metabolic pathways in the newborn organism, allowing a healthy growth. Among the array of hormones, glucocorticoids are transferred from plasma to milk in the new mother, and positively correlate to saliva levels (Kato et al., 1985; van der Voorn et al., 2016). Hence, glucocorticoids levels in milk reflect the circadian rhythm of maternal hypothalamic-pituitary-adrenal (HPA) axis (van der Voorn et al., 2016). Similarly, prolactin, the hormone that stimulates milk production, can also be detected in human milk, with higher concentration in foremilk compared to hindmilk (Cox et al., 1996). Prolactin release is stimulated by the baby's nipple suckling, therefore creating a positive loop mechanism for increasing milk availability (Crowley, 2015).

\subsection{The role of milk on child development}

Although, the research literature has provided evidence for the composition of human milk, as well as observations for changes in milk components during the whole period of lactation, it is still not fully understood how milk and its constituents can affect child growth, from infancy to late development. There is evidence showing that breast milk contributes to physical and cognitive neurodevelopment in the child (Agostoni et al., 2009; Quigley et al., 2012). In many studies children who receive breast milk, compared with those who are nourished with formula, have 
higher intelligence quotient (IQ), better school performance and higher income in adulthood (Horta et al., 2018). Moreover, the developmental benefits of breastfeeding appear to be proportional to the duration of lactation (Horta et al., 2018), therefore suggesting that a prolonged natural lactation may improve long-term brain functions.

These evidences seem to outline a clear association between breastfeeding and better developmental outcomes in children, however other aspects need to be taken into consideration to make an unbiased judgement on the role of breastfeeding on child development (Kramer et al., 2011). Indeed, mothers from difficult social backgrounds, characterized by low social support, unhealthy dietary patterns and low education level, are more likely to discontinue breastfeeding and choose formula-feeding (Taveras et al., 2003). As a consequence, children living in such adverse environment are more likely to be exposed to elevated risks of developing emotional and behavioural dysregulations (Garratt et al., 2017). Therefore, this suggest that although the beneficial effect of breast milk on child development has been established, further investigations are needed to distinguish the negative influence that disadvantaged socio-economic conditions have on children's growth, in addition to lack of breastfeeding.

\section{Maternal mental health, milk composition, and child development}

This is the first review summarising evidence collected from the available literature investigating either 1) an association between maternal perinatal depression, anxiety and stress, and breast milk composition, or 2) an association between breast milk composition and child development during three main developmental stages: infancy, toddlerhood and childhood.

We performed a search via PubMed of the literature published up to January 2019, considering cohort studies and case control studies, without any exclusion in terms of age and 
gender. No study characteristics or publication date restriction were imposed. Papers concerning animal models were excluded. In addition, the search was limited to English-language studies. We included papers from studies where analyses of milk composition and psychological maternal assessment or child neurodevelopment were assessed. Relevant key words included: "perinatal depression", "postpartum depression", "stress", “anxiety", "breast milk", “child", "infant”, "behavior", “cognition", “neurocognition", "brain development”, "motor development", "neurodevelopment".

This section of the review is organised into three subsections: the first one describing the influence of maternal psychological state on milk composition, the second one focussing on the influence of breast milk composition on child neurodevelopment, and finally a third one describing the intergenerational mother-milk-child link. In each subsection, we first describe the studies that assessed the respective associations and, secondly, we discuss the results comparing them to findings from the literature. A total of twenty-eight studies have been included in this review, among them fifteen investigate how maternal psychological state influences milk composition (Table 1), whereas fifteen studies investigate how breast milk composition affects child neurodevelopment and cognition (Table 2); two studies were included in both categories, as they reported both psychological assessment in mothers, as well as neurocognitive, behavioral and brainmotor assessment in children.

\subsection{Influence of maternal psychological state on milk composition}

\subsubsection{Perinatal depression}

Eleven studies assessed symptoms of perinatal depression: one study assessed prenatal depression (Keim et al., 2012), and ten studies conducted postnatal evaluation. Several breast milk components were investigated, including lipids, vitamins, immune proteins and hormones. 


\section{Lipids}

One study only described measures of L-PUFAs levels in breast milk (Keim et al., 2012). Prenatal depressive symptoms measured at 20 weeks of pregnancy, but not at 24 to 29 weeks, predicted low levels of DHA and total $\omega-3$ L-PUFAs in milk at 4 months. However, after adjusting for variables such as education, smoking, maternal age and income, only the association between depressive symptoms at 20 weeks and DHA levels remained significant (Keim et al., 2012). This is in line with results from a cross-national ecological study that merged together data collected from 16 different countries, in which prevalence of maternal depression and milk L-PUFAs levels were independently investigated (Hibbeln, 2002). In particular, they found low levels of milk DHA in those countries where the prevalence of maternal depression was high. In addition, they found a higher seafood consumption in those countries where the prevalence of perinatal depression was low. This last finding, however, is in contrast with the observational study from our review, conducted on 287 women living in USA (Keim et al., 2012), where quantity of $\omega$-3 L-PUFAs intake did not correlate with either maternal depression or L-PUFAs milk content. This perhaps suggests that maternal psychological state, rather than food consumption, when investigated at individual level, plays a major role in determining L-PUFAs milk composition.

\section{Vitamins, ions and metals}

One study investigated the association between postpartum depression and milk content of the B-6 vitamin and results were not significant. However, the study reported a positive correlation between maternal vitamin B-6 intake and milk B-6 levels (Boylan et al., 2002). This last result is in line with findings from another older study (Thomas et al., 1979), therefore suggesting that vitamin B-6 consumption, rather than maternal psychopathology, could be the strongest predictor of changes in milk vitamin composition. 
Two more studies, performed 10 years apart, investigated the association between postpartum depression and milk sodium levels. The first study did not report any association (Ozbek et al., 2008). On the contrary, in the second study, mothers with postpartum depression had higher sodium levels and sodium/potassium ratio (Serim Demirgoren et al., 2017). Finally, one study examined the association between postpartum depression and concentration of metals in breast milk. The study did not find any correlation between maternal depression and milk mercury levels at 2 months postpartum (Örün et al., 2012).

\section{Immune components}

Two studies investigated the association between postpartum depression and milk levels of the cytokine TGF $\beta 2$. Both studies showed that women with postpartum depression had increased levels of TGF $\beta 2$ in milk (Kondo et al., 2011; Shariat et al., 2017). Interestingly, a recent metaanalysis did not report any significant association between depressive status in general population and TGF $\beta 2$ levels in blood (Kohler et al., 2017). A possible explanation for these discrepancies might be due to the fact that milk levels of TGF $\beta 2$ are primarily regulated by local production of the cytokine from the mammary glands, rather than from peripheral immune cells (Hawkes et al., 2002), therefore, proposing maternal depression as a fundamental contributing factor in the regulation of the biological mechanisms involved in the production of milk TGF $\beta 2$ cytokine.

In addition to TGF $\beta 2$, three studies investigated the association between postpartum depression and milk sIgA levels, with one study reporting an increase of sIgA levels in depressed mothers (Hart et al., 2004), one study reporting no correlation (Groër et al., 1994) and one reporting a significant decrease of sIgA levels in depressed mothers (Kawano and Emori, 2015). Results from the last study are in line with previous evidence, showing a decrease in sIgA levels in faecal 
samples of children who were breastfed by depressed mothers (Kang et al., 2017). Although in this study sIgA levels were not measured in breast milk, faecal sIgA levels represents a good indicator of milk sIgA levels (Bridgman et al., 2016). Indeed, once ingested through milk sIgA does not get absorbed and its concentration remains constantly available until it gets expelled in the feces (Roux et al., 1977).

\section{Hormones}

To our knowledge, only one study examined the association between postpartum depression and milk cortisol levels, however the authors did not find any significant results (Groër et al., 1994). A more recent paper investigated the concentration of two other hormones, melatonin and prolactin, in breast milk. The authors found a trend towards an association between postpartum depression, and lower prolactin, and higher melatonin concentration in milk samples (Groër et al., 2005), although both results were not significant. With respect to melatonin, these findings are partially in contrast with previous research, showing a decrease in melatonin levels in plasma samples of postpartum depressed women (Parry et al., 2008). Although both milk and plasma melatonin follow the same circadian rhythm (Illnerova et al., 1993), the opposite findings suggest that melatonin levels in milk might be regulated by distinct pathophysiological patterns that are different from those involved in plasma.

\subsubsection{Perinatal anxiety}

\section{Ions}

Two studies investigated the correlation between postpartum maternal anxiety and ions concentration in breast milk. In both studies the authors found a positive association between postpartum state anxiety, but not trait anxiety, and milk sodium levels (Ozbek et al., 2008; Serim Demirgoren et al., 2017). Although both state and trait anxiety are common in the postpartum 
period (Giakoumaki et al., 2009), findings from the two above studies might suggest that the transient anxiety symptoms occurring postnatally in a specific moment ("state anxiety") might affect more prominently the composition of breast milk, compared to the individual's personality and proneness to anxiety ("trait anxiety"). Indeed, maternal milk is constantly subjected to shortterm changes, which are primarily influenced by the maternal physiological state (Khan, 2012; Khan et al., 2013). Therefore, addressing state rather than trait anxiety levels in the perinatal period might be a more useful indicator to investigate the influence of maternal anxiety on milk composition.

\section{Immune components}

Four papers investigated the association between maternal postpartum anxiety and concentrations of distinct immune components in breast milk. Among these, one paper found a significant positive correlation between milk TGF $\beta 2$ concentration and both postpartum state and trait anxiety (Shariat et al., 2017). Finally, three studies investigated the association between postnatal anxiety and milk sIgA concentration. Two studies did not find any significant correlation between maternal state or trait anxiety and sIgA (Groër et al., 1994), and state anxiety and sIgA milk levels (Hart et al., 2004). However, one study found a negative association between postpartum state and trait anxiety scores, and sIgA milk levels (Kawano and Emori, 2015). This is in contrast with results previously described where only state anxiety, but not trait anxiety, was associated with high ions levels in milk (Ozbek et al., 2008; Serim Demirgoren et al., 2017). Overall, this potentially suggests that maternal personality trait anxiety, which is stable and longlasting, can exert effect over time on milk immune components. 


\section{Hormones}

To our knowledge, only one paper examined the correlation between maternal postpartum state or trait anxiety and cortisol levels in breast milk, however results did not show any significant association (Groër et al., 1994). In addition, one study investigated the association between postpartum anxiety and opioids concentration in breast milk. The authors found a negative association between postpartum state anxiety and colostral $\beta$-endorphin in milk, but only when mothers who underwent caesarean section were excluded from the analysis (Zanardo et al., 2001). This result perhaps suggests that an increase in pain, due to natural birth, might induce a higher production of milk $\beta$-endorphin, when compared to the caesarean section, which confound the possible association with state anxiety. In the same paper, no significant association was found between postpartum trait anxiety and $\beta$-endorphin milk content (Zanardo et al., 2001). This finding is in accordance with results previously mentioned, where high level of milk sodium correlated with state anxiety only (Ozbek et al., 2008; Serim Demirgoren et al., 2017), and support the hypothesis that state, but not trait anxiety, might be the strongest predictor of milk content of some nonimmunological molecules, such as sodium and $\beta$-endorphin.

\subsubsection{Perinatal stress}

\section{Immune components}

Three studies investigated the association between postpartum stress and milk immune components. Two of these studies found a positive association between high maternal postpartum stress and an increase in milk sIgA levels (Groër et al., 2004; O'Connor et al., 1998). This is surprising since sIgA is a well-known anti-inflammatory agent (Monteiro, 2014). However, this might represent an example of protective mechanism activated by the mothers, that upon exposure to stressful challenges start to produce higher levels of milk sIgA to protect the infant against maternal stress-related changes. 
In contrast, a third study did not find any significant correlation between postpartum stress and milk sIgA levels (Thibeau et al., 2016). However, the authors found a negative correlation between maternal postpartum stress and milk macrophage inflammatory protein-1-alpha (MIP-1 $\alpha$ ) and tumor necrosis factor $\alpha(\mathrm{TNF}-\alpha)$ levels at day 3 postnatally. Furthermore, a predictive positive association between maternal stress at day 3 postnatally, and milk interleukin (IL)- 8 and MIP-1 $\alpha$ content at day 14 was highlighted. No significant association was found between maternal postpartum stress and milk levels of other immune components, including IL-4, IL-6, IL-10 and the monocyte chemotactic protein-1.

\section{Hormones}

To our knowledge only one paper investigated the association between maternal postpartum stress and concentration of hormones in breast milk. Interestingly, they found a trend towards an association between maternal postpartum stress and lower milk prolactin and higher milk melatonin (Groër et al., 2005), however results were not significant. An increase of milk prolactin levels in the stressed mothers is in accordance with previous evidence showing an association between stress and higher incidence of hyperprolactinemia in general population (Levine and Muneyyirci-Delale, 2018; Sonino et al., 2004). However further investigations are needed to better understand the underlying mechanism through which stress, experienced during the perinatal period, can influence the hormonal milk content.

\subsection{Influence of breast milk composition on child neurodevelopment}

In this section of the review we summarise and discuss papers investigating the effect of breast milk composition on child neurodevelopmental status, behavior and cognition. Overall, we collected fifteen papers. A variety of assessment tools were used in order to test child performance during the developmental stages of infancy, toddlerhood and childhood; for example, from birth 
until one year of age, the Brazelton Neonatal Behavioral Assessment Scale (NBAS) and the Rothbart Revised Infant Behavior Questionnaire (IBQ-R); from one year to three years old, the Bayley Scales of Infants and Toddlers Development and the Ages and Stages Questionnaire (ASQ), as well as videotaped free-play sessions; and from four years to twelve years old, the Kaufman Assessment Battery for Children (K-ABC) and the Wechsler Intelligence Scale for Children - Third edition (WISC-III).

\subsubsection{Infancy}

\section{Lipids and Vitamins}

Using the Brazelton Neonatal Behavioral Assessment Scale (NBAS), the first study found a positive correlation between high levels of milk L-PUFA DHA and superior arousal in the infant (Hart et al., 2006). In contrast, using the Fagan Test of Infant Intelligence another study did not find any association between concentration of L-PUFAs in milk and infant cognitive function (Helland et al., 2001). In addition to L-PUFAs, two more studies investigated a possible association between milk levels of vitamin B-6 and child behavioral response using the NBAS scale. The first study found a significant correlation between high levels of vitamin B-6 and higher consolability of the infant, as well as longer time to build-up distress and irritability when exposing the infant to aversive stimuli (McCullough et al., 1990). Similarly, the second study found a positive association between breast milk levels of B-6 vitamin and increased infant habituation to outer stimuli, as well as infant's ability to control involuntary autonomic responses (Boylan et al., 2002). Overall, findings suggest that macronutrients, like L-PUFA DHA, are involved in infant attention, as already reported in previous studies, conducted on infants, investigating the effect of pre- and postnatal DHA exposure (Colombo et al., 2012, 2004). On the other hand micronutrients, like the vitamin B6, might play an important role in the infant ability to deal with stressful challenges, similarly to what has been proposed for adults (Mccarty, 2000). 


\section{Immune components}

With respect to milk immune components, one study using the NBAS found a positive association between high milk sIgA content and infant responsiveness to visual and auditory stimuli (Hart et al., 2004). This is interesting, and it might suggest a potential role for sIgA in brain development and neuroplasticity. One hypothesis might be that milk sIgA, although is not absorbed in the intestine of the infant (Roux et al., 1977), can still regulate the composition of the gut microbiome, promoting symbiosis between bacteria (Nakajima et al., 2018), and ultimately reducing the expression of distinct pro-inflammatory cytokines, like TNF- $\alpha$, both at gut and brain level (Sun et al., 2018). Indeed, a reduced neuroinflammation has been shown to ameliorate both neurogenesis and brain plasticity (Borsini et al., 2018, 2017, 2015; Innes et al., 2019; Zunszain et al., 2012), therefore potentially leading to infant better performances in cognitive tasks.

\section{Hormones}

To our knowledge only two studies investigated the association between maternal milk cortisol level and infant neurobehavioral development. The first study, using the Rothbart Revised Infant Behavior Questionnaire (IBQ-R), found a significant positive association between milk cortisol levels and negative emotional and behavioral reactions from the infant, and only a trend for a negative association between cortisol milk level and infant reactivity (Grey et al., 2013). In contrast, using the NBAS scale the second study found a positive correlation between high levels of milk cortisol and improved ability to control involuntary autonomic responses (Hart et al., 2004). This last evidence is supported by two other studies which reported a positive association between infant cortisol levels in saliva (Magnano et al., 1992) and plasma (Gunnar et al., 1987) and, respectively, infant arousal, measured as the HPA axis activation to a stressor, and NBAS scores. Interestingly, in all of the above studies the concentration of cortisol was around normal levels, roughly $0.4 \mathrm{ug} / \mathrm{dL}$ in breast milk and saliva (Hart et al., 2004; Magnano et al., 1992), and 9ug/dL in 
plasma (Gunnar et al., 1987), therefore suggesting that cortisol, within certain ranges, plays a positive role in infant emotional, behavioral and autonomic functions. Indeed, a particular infant congenital disorder, the Smith-Lemli-Opitz syndrome disease, which can induce high plasma cortisol levels, up to $34 \mathrm{ug} / \mathrm{dL}$ (Kumar et al., 2012), has been associated with cognitive impairments (Diaz-stransky and Tierney, 2012), as well as disorder of the infant's autonomic nervous system (Sinclair et al., 1968).

\subsubsection{Toddlerhood}

\section{Lipids}

Six studies investigated a possible association between milk levels of L-PUFAs and child mental development using the Mental Developmental Index (MDI) of the Bayley Scales of Infant and Toddler Development, which evaluates several aspects related to toddler cognitive development, including memory, habituation and problem solving, through the assignment of a score directly proportional to the quality of the toddler's performance. Half of the studies did not find a significant association between milk L-PUFAs levels and MDI scores (Hurtado et al., 2015; Jensen et al., 2005; Westerberg et al., 2011). In contrast, three studies found a significant association between high total milk fat content (Agostoni et al., 2001) or DHA milk levels (Makrides et al., 2009) and high MDI scores; and a trend for an association between high levels of $\omega$-3 L-PUFAs and $\omega-3 / \omega-6$ L-PUFAs ratio and high MDI scores (Guxens et al., 2011). In accordance, these findings are supported by a recent meta-analysis, which reports a trend for a positive correlation between formula L-PUFAs supplementation and increased mental development in toddlers (Qawasmi et al., 2012).

Using the Psychomotor Development Index (PDI) of the Bayley scale, which tests for fine and gross motor development, one study found a positive association between high milk DHA 
levels, low ARA levels, and higher PDI scores, which indicates better psychomotor coordination (Jensen et al., 2005). In contrast with this finding, three more studies did not find any significant association between L-PUFA milk concentration and PDI scores (Agostoni et al., 2001; Hurtado et al., 2015; Makrides et al., 2009). This is in line with the previously mentioned meta-analysis by Qawasmi et al., which also did not find any significant association between formula L-PUFAs supplementation and toddlers' psychomotor development (Qawasmi et al., 2012), therefore suggesting that milk L-PUFAs content plays a role only on mental development, but not on psychomotor development, at least if measured in toddlers.

Finally, two of the above-mentioned studies performed also additional investigations. The first study assessed the association between milk L-PUFAs and mental and motor development, using the Ages and Stages Questionnaire (ASQ). The authors reported no significant association between milk levels of L-PUFAs and the ASQ scores, however they found a positive association between milk L-PUFAs levels and increased child attention during free-play sessions (Westerberg et al., 2011). Finally, the second study assessed the association between milk L-PUFAs levels and child gross motor development (Gesell Developmental Inventory scale), and language development and visual-motor problem solving abilities (Clinical Adaptive Test/Clinical Linguistic and Auditory Milestone Scale). However, the authors did not find any significant results among any of those associations (Jensen et al., 2005). These findings therefore confirm our previous hypothesis that milk L-PUFAs content is primarily involved in conferring normal mental development in toddlers, via increasing attention performances and alertness, but without no particular influence on toddlers' psychomotor skills. 


\subsubsection{Childhood}

\section{Lipids}

To our knowledge three studies investigated the association between milk L-PUFA concentrations and child development. The first study assessed Intelligence Quotient (IQ) using the Kaufman Assessment Battery for Children (K-ABC) test, and found an association between high DHA and low ARA milk levels and better performance in problem solving and information processing abilities in children (Helland et al., 2003). Similarly, another study found a positive correlation between colostral content of L-PUFAs and IQ in children. In particular, children who received milk with higher DHA/ARA ratio of levels scored better in the Wechsler Intelligence Scale for Children. No significant association was found for L-PUFAs contained in mature milk and IQ scores (Gustafsson et al., 2004). Finally, using the Dutch CITO-elementary Test, one study found an association between high milk total $\omega$-3 L-PUFAs, DHA and DHA/ARA ratio, and better school performance in 12 years old girls (Dalmeijer et al., 2016), therefore suggesting the ability for milk L-PUFAs to exert long term effects on child development, up to early adolescence.

\subsection{Mother-milk-child link}

We found only two studies that investigated both the association between maternal psychopathology and milk composition, and between milk composition and child development. The first study did not find any association between postpartum depression and milk vitamin B-6 levels, but only between milk B-6 levels and infant's involuntary responses (Boylan et al., 2002). However, the second study identified an association between postpartum depression and high milk sIgA, as well as between high milk sIgA and improved infant alertness (Hart et al., 2004). Although, the authors did not investigate any direct effect between maternal depression and infant performance, indirect analyses seem to propose milk sIgA as a key biological link between mother and child interaction. Of relevance, the finding reported in this study suggests that depressed 
mothers, who have a high milk sIgA levels, have infants with improved alertness. This is surprising if considering that, in general, infants of depressed mothers receive lower scores on orienting to the live face/voice stimulus and on the alertness items of behavioural assessment, which is usually attributed to the less responsive behavior of the depressed mothers (Field et al., 2010). However, we hypothesise that the results from the study in our review might be explained by the previously discussed anti-inflammatory and, ultimately, neuroprotective role of sIgA (Nakajima et al., 2018; Sun et al., 2018). Indeed, an increase in milk sIgA levels in depressed mothers might represent a form of protective mechanism to defend the infant against any detrimental changes occurring in the depressed mother, and which can be transmitted during the stages of breastfeeding (Goldman et al., 1990).

\section{Conclusion}

To our knowledge this is the first review summarizing current evidence showing a potential link between maternal psychopathologies and child development, giving particular attention to breast milk composition. Overall, our findings confirm and extend evidence for the contributing role of milk composition on the regulation of child development, from the early stages of infancy until late childhood. Moreover, findings from our review suggest that breast milk composition might also play a role in the proposed association, and it deserves further consideration. Milk factors like L-PUFAs vitamins, immune components, such as sIgA, and hormones, like cortisol, investigated in this review, have all been identified as regulatory mechanisms in the context of psychiatric disorders, as well as in conditions associated with alteration in both brain development and behavior.

This review is limited in part by the inclusion of only 28 studies, as a consequence of the narrow available literature surrounding this field, and by the heterogeneity of the studies design, and 
different assessment tools employed when evaluating maternal psychopathology and child development. Despite these limitations this review sheds light on the impact of perinatal psychopathologies on a wide array of breast milk components, which if altered in their levels can severely affect infant development. Therefore, we would argue that the molecular mechanisms, by which milk nutritional constituents and bioactive factors may be altered by maternal psychopathological status, should be the focus of future investigations. These would allow a better understanding of the ethiopathology of perinatal disorders and their consequence on the child, leading to the identification of novel therapeutic approaches for the treatment of both the mother and the child.

Acknowledgments: Dr Borsini has received research funding by the Medical Research Council (UK) (grant MR/N029488/1) and by the National Institute for Health Research (NIHR) Biomedical Research Centre at South London and Maudsley NHS Foundation Trust and King's College London. Professor Pariante is funded by the UK National Institute for Health Research (NIHR) Biomedical Research Centre at the South London and Maudsley NHS Foundation Trust and King's College London, the UK Medical Research Council (grants MR/L014815/1, MR/J002739/1and MR/N029488/1) and the Psychiatry Research Trust. 


\section{References}

Agostoni, C., Braegger, C., Decsi, T., Kolacek, S., Koletzko, B., Michaelsen, K.F., Mihatsch, W., Moreno, L.A., Puntis, J., Shamir, R., Szajewska, H., Turck, D., Van Goudoever, J., 2009. Breast-feeding: A commentary by the espghan Committee on Nutrition. J. Pediatr. Gastroenterol. Nutr. 49, 112-125. https://doi.org/10.1097/MPG.0b013e31819f1e05

Agostoni, C., Marangoni, F., Lammardo, A.M., Giovannini, M., Riva, E., Galli, C., 2001. Breastfeeding duration, milk fat composition and developmental indices at 1 year of life among breastfed infants. Prostaglandins Leukot. Essent. Fat. Acids 64, 105-109. https://doi.org/10.1054/plef.2001.0248

American Psychiatric Association, 2013. Diagnostic and Statistical Manual of Mental Disorders, 5th Edition (DSM-5). Diagnostic Stat. Man. Ment. Disord. 4th Ed. TR. https://doi.org/10.1176/appi.books.9780890425596.744053

Ballard, O., Morrow, A.L., 2013. Human Milk Composition. Nutrients and Bioactive Factors. Pediatr. Clin. North Am. 60, 49-74. https://doi.org/10.1016/j.pcl.2012.10.002

Berg, J.P. Van Den, Westerbeek, E.A.M., Smits, G.P., Klis, F.R.M. Van Der, Berbers, G.A.M., Elburg, R.M. Van, 2014. Lower Transplacental Antibody Transport for Measles, Mumps , Rubella and Varicella Zoster in Very Preterm Infants 9. https://doi.org/10.1371/journal.pone.0094714

Biaggi, A., Conroy, S., Pawlby, S., Pariante, C.M., 2016. Identifying the women at risk of antenatal anxiety and depression: A systematic review. J. Affect. Disord. 191, 62-77. https://doi.org/10.1016/j.jad.2015.11.014

Birch, E.E., Castañeda, Y.S., Wheaton, D.H., Birch, D.G., Uauy, R.D., Hoffman, D.R., 2005. Visual maturation of term infants fed long-chain polyunsaturated fatty acid-supplemented or control formula for 12 mo. Am. J. Clin. Nutr. https://doi.org/10.1093/ajcn/81.4.871

Bobo, W. V., Yawn, B.P., 2014. Concise review for physicians and other clinicians: Postpartum depression. Mayo Clin. Proc. 89, 835-844. https://doi.org/10.1016/j.mayocp.2014.01.027

Borsini, A., Alboni, S., Horowitz, M.A., Tojo, L.M., Cannazza, G., Su, K., Pariante, C.M., Zunszain, P.A., 2017. Rescue of IL-1 b -induced reduction of human neurogenesis by omega-3 fatty acids and antidepressants. Brain Behav. Immun. 65, 230-238. https://doi.org/10.1016/j.bbi.2017.05.006 
Borsini, A., Cattaneo, A., Malpighi, C., Thuret, S., Harrison, N.A., Zunszain, P.A., Pariante, C.M., 2018. Interferon-alpha reduces human hippocampal neurogenesis and increases apoptosis via activation of distinct STAT1-dependent mechanisms. Int. J. Neuropsychopharmacol. 21, 187-200. https://doi.org/10.1093/ijnp/pyx083

Borsini, A., Zunszain, P.A., Thuret, S., Pariante, C.M., 2015. The role of inflammatory cytokines as key modulators of neurogenesis. Trends Neurosci. 38, 145-157. https://doi.org/10.1016/j.tins.2014.12.006

Boylan, L.M., Hart, S., Porter, K.B., Driskell, J.A., 2002. Vitamin B-6 content of breast milk and neonatal behavioral functioning. J. Am. Diet. Assoc. https://doi.org/10.1016/S0002-8223(02)90317-2

Bridgman, S.L., Konya, T., Azad, M.B., Sears, M.R., Becker, A.B., Turvey, S.E., Mandhane, P.J., Subbarao, P., 2016. Infant gut immunity : a preliminary study of IgA associations with breastfeeding 7, 68-72. https://doi.org/10.1017/S2040174415007862

Bronson, S.L., Bale, T.L., 2015. The Placenta as a Mediator of Stress Effects on Neurodevelopmental Reprogramming 41, 207-218. https://doi.org/10.1038/npp.2015.231

Butte, N.F., King, J.C., 2005. Energy requirements during pregnancy and lactation. Public Health Nutr. https://doi.org/10.1079/PHN2005793

Cattaneo, A., Cattane, N., Malpighi, C., Czamara, D., Suarez, A., Mariani, N., Kajantie, E., Luoni, A., Eriksson, J.G., Lahti, J., Mondelli, V., Dazzan, P., Räikkönen, K., Binder, E.B., Riva, M.A., Pariante, C.M., 2018. FoxO1, A2M, and TGF- $\beta 1$ : three novel genes predicting depression in gene $\mathrm{X}$ environment interactions are identified using cross-species and cross-tissues transcriptomic and miRNomic analyses. Mol. Psychiatry 1-17. https://doi.org/10.1038/s41380-017-0002-4

Cecil, C.A.M., Lysenko, L.J., Jaffee, S.R., Smith, R.G., Relton, C.L., Woodward, G., Mcardle, W., Mill, J., Barker, E.D., 2015. Environmental risk, Oxytocin Receptor Gene (OXTR) methylation and youth callous-unemotional traits: A 13-year longitudinal study. Mol. Psychiatry 19, 1071-1077. https://doi.org/10.1038/mp.2014.95.Environmental

Colombo, J., Carlson, S.E., Cheatham, C.L., Fitzgerald-gustafson, K.M., Kepler, A., Doty, T., 2012. Long Chain Polyunsaturated Fatty Acid Supplementation in Infancy Reduces Heart Rate and Positively Affects Distribution of Attention 70, 406-410. https://doi.org/10.1203/PDR.0b013e31822a59f5.Long 
Colombo, J., Kannass, K.N., Shaddy, D.J., Kundurthi, S., Maikranz, J.M., Christa, J., Blaga, O.M., Carlson, S.E., 2004. Maternal DHA and the Development of Attention in Infancy and Toddlerhood 75, 12541267.

Coryell, M.N., Harris, M.E., Miller, S., Williams, H.H., Macy, I.G., 1945. NICOTINIC ACID, PANTOTHENIC ACID AND BIOTIN CONTENTS OF COLOSTRUM AND MATURE HUMAN MILK. Am J Dis Child 218.

Cox, D.B., Owens, R.A., Hartmann, P.E., 1996. Blood And Milk Prolactin And The Rate Of Milk Synthesis In Women 1007-1020.

Crowley, W.R., 2015. Neuroendocrine Regulation of Lactation and Milk Production 5, 255-291. https://doi.org/10.1002/cphy.c140029

Dalmeijer, G.W., Wijga, A.H., Gehring, U., Renders, C.M., Koppelman, G.H., Smit, H.A., van Rossem, L., 2016. Fatty acid composition in breastfeeding and school performance in children aged 12 years. Eur. J. Nutr. 55, 2199-2207. https://doi.org/10.1007/s00394-015-1030-y

Diaz-stransky, A., Tierney, E., 2012. Cognitive and Behavioral Aspects of Smith - Lemli - Opitz Syndrome. Am. J. Med. Genet. 300, 295-300. https://doi.org/10.1002/ajmc.31342

Dror, D.K., Allen, L.H., 2018. Overview of Nutrients in Human Milk. Adv. Nutr. https://doi.org/10.1093/advances/nmy022

Evans, J., Heron, J., Francomb, H., Oke, S., Golding, J., Kendall, R., Wainwright, S., Hailey, A., Shannon, B., Pitt, B., Cooper, P., Campbell, E., Day, A., Kennerley, H., Bond, A., O’Hara, M., Zekoski, E., Phillips, L., Wright, E., Sinclair, D., Murray, L., Murray, L., Sinclair, D., Cooper, P., Ducournau, P., Turner, P., O’Hara, M., Neunaber, D., Zekoski, E., Hobfoll, S., Ritter, C., Lavin, J., Hulsizer, M., Cameron, R., Cox, J., Connor, Y., Kendell, R., Watson, J., Elliott, S., Rugg, A., Brough, D., Teixeira, J., Fisk, N., Glover, V., Cox, J., Holden, J., Sagovsky, R., Crown, S., Crisp, A., Thorpe, K., Fergusson, D., Horwood, J., Thorpe, K., Cooper, P., Murray, L., Mynors-Wallis, L., Gath, D., Day, A., Baker, F., Spinelli, M., 2001. Cohort study of depressed mood during pregnancy and after childbirth. BMJ 323, 257-60. https://doi.org/10.1136/bmj.323.7307.257

Fairbrother, N., Janssen, P., Antony, M.M., Tucker, E., Young, A.H., 2016. Perinatal anxiety disorder 
prevalence and incidence. J. Affect. Disord. 200, 148-155. https://doi.org/10.1016/j.jad.2015.12.082

Field, T., 2011. Postpartum Depression Effects on Early Interactions, Parenting, and Safety Practices: A Review 33, 1-9. https://doi.org/10.1016/j.infbeh.2009.10.005.Postpartum

Field, T., Diego, M., Hernandez-reif, M., 2010. Infants of depressed mothers are less responsive to faces and voices: A review. Infant Behav. Dev. 32, 239-244. https://doi.org/10.1016/j.infbeh.2009.03.005.Infants

Garratt, E.A., Chandola, T., Purdam, K., Wood, A.M., 2017. Income and Social Rank Influence UK Children's Behavioral Problems: A Longitudinal Analysis. Child Dev. 88, 1302-1320. https://doi.org/10.1111/cdev.12649

Gavin, N.I., Gaynes, B.N., Lohr, K.N., Meltzer-brody, S., Gartlehner, G., Swinson, T., 2005. A Systematic Review of Prevalence and Incidence 106, 1071-1083.

Gephart, S.M., Weller, M., 2014. Colostrum as Oral Immune Therapy to Promote Neonatal Health 14, 4451. https://doi.org/10.1097/ANC.0000000000000052

Giakoumaki, O., Vasilaki, K., Lili, L., Skouroliakou, M., Liosis, G., Vasilaki, K., Lili, L., Skouroliakou, M., The, G.L., 2009. The role of maternal anxiety in the early postpartum period : screening for anxiety and depressive symptomatology in Greece 8942, 20-28. https://doi.org/10.1080/01674820802604839

Gidrewicz, D.A., Fenton, T.R., 2014. A systematic review and meta-analysis of the nutrient content of preterm and term breast milk. BMC Pediatr. 14, 1-14. https://doi.org/10.1186/1471-2431-14-216.

Goldman, A.S., Goldblum, R.M., Hanson, L.A., 1990. Anti-inflammatory systems in human milk. Adv Exp Med Biol.

Grey, K.R., Davis, E.P., Sandman, C.A., Glynn, L.M., 2013. Human milk cortisol is associated with infant temperament. Psychoneuroendocrinology 38, 1178-1185. https://doi.org/10.1016/j.psyneuen.2012.11.002

Groër, M., Davis, M., Casey, K., Short, B., Smith, K., Groer, S., 2005. Neuroendocrine and Immune Relationships in Postpartum Fatigue 25, 1-6.

Groër, M., Davis, M., Steele, K., 2004. Associations between human milk SIgA and maternal immune, infectious, endocrine, and stress variables. J. Hum. Lact. https://doi.org/10.1177/0890334404264104

Groër, M.W., Humenick, S., Hill, P.D., 1994. Characterizations and psychoneuroimmunologic implications 
of secretory immunoglobulin A and cortisol in preterm and term breast milk. J. Perinat. Neonatal Nurs. https://doi.org/10.1097/00005237-199403000-00005

Gunnar, M.R., Isensee, J., Fust, L.S., 1987. Adrenocortical Activity and the Brazelton Neonatal Assessment Scale : Moderating Effects of the Newborn's Biomedical Status. Child Dev. 58, 1448-1458. https://doi.org/10.1111/j.1467-8624.1987.tb03857.x

Gustafsson, P.A., Duchén, K., Birberg, U., Karlsson, T., 2004. Breastfeeding, very long polyunsaturated fatty acids (PUFA) and IQ at 6 1/2 years of age. Acta Paediatr. Int. J. Paediatr. 93, 1280-1287. https://doi.org/10.1080/08035250410033123

Guxens, M., Mendez, M.A., Molto-Puigmarti, C., Julvez, J., Garcia-Esteban, R., Forns, J., Ferrer, M., Vrijheid, M., Lopez-Sabater, M.C., Sunyer, J., 2011. Breastfeeding, Long-Chain Polyunsaturated Fatty Acids in Colostrum, and Infant Mental Development. Pediatrics 128, e880-e889. https://doi.org/10.1542/peds.2010-1633

Hadley, K.B., Ryan, A.S., Forsyth, S., Gautier, S., Salem, N., 2016. The essentiality of arachidonic acid in infant development. Nutrients 8. https://doi.org/10.3390/nu8040216

Hair, A.B., Hawthorne, K.M., Chetta, K.E., Abrams, S.A., 2013. Human milk feeding supports adequate growth in infants $\leq 1250$ grams birth weight. BMC Res. Notes.

Hanson, L.A., Söderström, T., 1981. Human milk: Defense against infection. Prog. Clin. Biol. Res.

Hart, S., Boylan, L.M., Border, B., Carroll, S.R., McGunegle, D., Lampe, R.M., 2004. Breast milk levels of cortisol and Secretory Immunoglobulin A (SIgA) differ with maternal mood and infant neurobehavioral functioning. Infant Behav. Dev. 27, 101-106. https://doi.org/10.1016/j.infbeh.2003.06.002

Hart, S.L., Boylan, L.M., Carroll, S.R., Musick, Y.A., Kuratko, C., Border, B.G., Lampe, R.M., 2006. Brief report: Newborn behavior differs with decosahexaenoic acid levels in breast milk. J. Pediatr. Psychol. 31, 221-226. https://doi.org/10.1093/jpepsy/jsj069

Hawkes, J.S., Bryan, D.L., Gibson, R.A., 2002. Variations in transforming growth factor beta in human milk are not related to levels in plasma. Cytokine. https://doi.org/10.1006/cyto.2002.0987

Helland, I.B., Saugstad, O.D., Smith, L., Saarem, K., 2001. Similar Effects on Infants of n-3 and n-6 Fatty Acids Supplementation to Pregnant and Lactating Women. Pediatrics 108, 1-10. 
Helland, I.B., Smith, L., Saarem, K., Saugstad, O.D., Drevon, C.A., 2003. Maternal Supplementation With Very-Long-Chain n-3 Fatty Acids During Pregnancy and Lactation Augments Children's IQ at 4 Years of Age. Pediatrics 111, e39-e44. https://doi.org/10.1542/peds.111.1.e39

Hibbeln, J.R., 2002. Seafood consumption, the DHA content of mothers' milk and prevalence rates of postpartum depression: A cross-national, ecological analysis. J. Affect. Disord. 69, 15-29. https://doi.org/10.1016/S0165-0327(01)00374-3

Horta, B.L., De Sousa, B.A., De Mola, C.L., 2018. Breastfeeding and neurodevelopmental outcomes. Curr. Opin. Clin. Nutr. Metab. Care 21, 174-178. https://doi.org/10.1097/MCO.0000000000000453

Hurtado, J.A., Iznaola, C., Peña, M., Ruíz, J., Peña-Quintana, L., Kajarabille, N., Rodriguez-Santana, Y., Sanjurjo, P., Aldámiz-Echevarría, L., Ochoa, J., Lara-Villoslada, F., 2015. Effects of maternal $\Omega-3$ supplementation on fatty acids and on visual and cognitive development. J. Pediatr. Gastroenterol. Nutr. 61, 472-480. https://doi.org/10.1097/MPG.0000000000000864

Illnerova, H., Buresova, M., Presl, J., 1993. Melatonin Rhythm in Human Milk. J. Clin. Endocrinol. Metab. $77,838-841$.

Innes, S., Pariante, C.M., Borsini, A., 2019. Microglial-driven changes in synaptic plasticity : A possible role in major depressive disorder. Psychoneuroendocrinology 102, 236-247. https://doi.org/10.1016/j.psyneuen.2018.12.233

Jenness, R., 1979. The composition of human milk. Semin. Perinatol.

Jensen, C.L., Voigt, R.G., Prager, T.C., Zou, Y., Fraley, J.K., Rozelle, J.C., Turcich, M.R., Llorente, A.M., Anderson, R.E., Heird, W.C., 2005. Effects of maternal docosahexaenoic acid supplementation on visual function and growth of breast-fed term infants. Am. J. Clin. Nutr. 82, 125-132. https://doi.org/Cited By (since 1996) 88 Export Date 27 May 2012

Kang, L.J., Koleva, P.T., Field, C.J., Giesbrecht, G.F., Wine, E., Becker, A.B., Mandhane, P.J., Turvey, S.E., Subbarao, P., Sears, M.R., Scott, J.A., Kozyrskyj, A.L., Investigators, C.S., 2017. Maternal depressive symptoms linked to reduced fecal Immunoglobulin A concentrations in infants. Brain Behav. Immun. 1-9. https://doi.org/10.1016/j.bbi.2017.10.007

Kato, E.A., Ray-Sea Hsu, B., Raymoure, W.J., Kuhn, R.W., 1985. Evidence for the direct transfer of 
corticosteroid-binding globulin from plasma to whey in the guinea pig. Endocrinology.

https://doi.org/10.1210/endo-117-4-1404

Kawano, A., Emori, Y., 2015. The Relationship Between Maternal Postpartum Psychological State and Breast Milk Secretory Immunoglobulin A Level. J. Am. Psychiatr. Nurses Assoc. 21, 23-30. https://doi.org/10.1177/1078390314566882

Kawano, A., Emori, Y., Miyagawa, S., 2009. Association between stress-related substances in saliva and immune substances in breast milk in Puerperae. Biol. Res. Nurs. 10, 350-355. https://doi.org/10.1177/1099800409331892

Kazemi, T., 2016. A review on postpartum depression. Res. J. Pharm. Biol. Chem. Sci. 7, 287-295. https://doi.org/10.4088/PCC.v01n0103

Keim, S. a, Daniels, J.L., Siega-Riz, A.M., Dole, N., Herring, A.H., Scheidt, P.C., 2012. Depressive symptoms during pregnancy and the concentration of fatty acids in breast milk. J. Hum. Lact. https://doi.org/10.1177/0890334411424727

Kelishadi, R., Hadi, B., Iranpour, R., Khosravi-Darani, K., Mirmoghtadaee, P., Farajian, S., Poursafa, P., 2012. A study on lipid content and fatty acid of breast milk and its association with mother's diet composition. J. Res. Med. Sci. 17, 824-827. https://doi.org/http://dx.doi.org/10.1016/j.jebo.2011.06.003

Khan, S., 2012. Short- term variations in breastmilk composition: Associations with feeding patterns and gastric emptying in term infants. PhD Diss. Univ. West. Aust.

Khan, S., Prime, D.K., Hepworth, A.R., Lai, C.T., Trengove, N.J., Hartmann, P.E., 2013. Investigation of short-term variations in term breast milk composition during repeated breast expression sessions. J. Hum. Lact. 29, 196-204. https://doi.org/10.1177/0890334412470213

Kohler, C., Freitas, T., De Andrade, N., Liu, C., Fernandes, B., Stubbs, B., Solmi, M., Veronese, N., Herrmann, N., Raison, C., Miller, B., Lanctot, K., Carvalgo, A., 2017. Peripheral cytokine and chemokine alterations in depression : a meta-analysis of 82 studies 373-387. https://doi.org/10.1111/acps. 12698

Kondo, N., Suda, Y., Nakao, A., Oh-Oka, K., Suzuki, K., Ishimaru, K., Sato, M., Tanaka, T., Nagai, A., 
Yamagata, Z., 2011. Maternal psychosocial factors determining the concentrations of transforming growth factor-beta in breast milk. Pediatr. Allergy Immunol. 22, 853-861.

https://doi.org/10.1111/j.1399-3038.2011.01194.x

Kramer, M.S., Fombonne, E., Matush, L., Bogdanovich, N., Dahhou, M., Platt, R.W., 2011. Long-term behavioural consequences of infant feeding: The limits of observational studies. Paediatr. Perinat. Epidemiol. https://doi.org/10.1111/j.1365-3016.2011.01211.x

Kumar, S., Suthar, R., Panigrahi, I., 2012. Hypercortisolism and hypothyroidism in an infant with SmithLemli-Opitz syndrome 25, 1001-1005. https://doi.org/10.1515/jpem-2012-0099

Levine, S., Muneyyirci-Delale, O., 2018. Stress-Induced Hyperprolactinemia : Pathophysiology and Clinical Approach 2018.

Loomans, E.M., van Dijk, A.E., Vrijkotte, T.G.M., van Eijsden, M., Stronks, K., Gemke, R.J.B.J., Van den Bergh, B.R.H., 2012. Psychosocial stress during pregnancy is related to adverse birth outcomes : results from a large multi-ethnic community-based birth cohort. Eur. J. Public Health 23, 485-491. https://doi.org/10.1093/eurpub/cks097

Magnano, C.L., Gardner, J.M., Karmel, B.Z., 1992. Differences in salivary cortisol levels in cocaine- exposed and noncocaine- exposed NICU infants. Dev. Psychobiol. https://doi.org/10.1002/dev.420250203

Makrides, M., Gibson, R.A., Mcphee, A.J., Collins, C.T., Davis, P.G., Doyle, L.W., Colditz, P.B., Morris, S., Smithers, L.G., Willson, K., Ryan, P., 2009. Neurodevelopmental Outcomes of Preterm Infants Fed High-Dose Docosahexaenoic Acid 301, 175-182.

Makrides, M., Neumann, M.A., Byard, R.W., Simmer, K., Gibson, R.A., 1994. Fatty acid composition of brain, retina, and erythrocytes in breast- and formula-fed infants. Am. J. Clin. Nutr. https://doi.org/10.1093/ajcn/60.2.189

Mccarty, M.F., 2000. High-dose pyridoxine as an "anti- stress" strategy 54, 803-807. https://doi.org/10.1054/mehy.1999.0955

McCullough, A.L., Kirksey, A., Wachs, T.D., McCabe, G.P., Bassily, N.S., Bishry, Z., Galal, O.M., Harrison, G.G., Jerome, N.W., 1990. Vitamin B-6 status of Egyptian mothers: Relation to infant 
behavior and maternal-infant interactions. Am. J. Clin. Nutr. https://doi.org/10.1093/ajcn/51.6.1067

Meltzer-brody, S., 2011. New insights into perinatal depression: pathogenesis and treatment during pregnancy and postpartum. Dialogues Clin. Neurosci. 89-100.

Miller, R.L., Pallant, J.F., Negri, L.M., 2006. Anxiety and stress in the postpartum : Is there more to postnatal distress than depression ? 11, 1-11. https://doi.org/10.1186/1471-244X-6-12

Monteiro, R.C., 2014. Immunoglobulin A as an anti-inflammatory agent. Clin. Exp. Immunol. 178, 108-110. https://doi.org/10.1111/cei.12531

Mulligan, C.J., D’Errico, N.C., Stees, J., Hughes, D.A., 2012. Methylation changes at NR3C1 in newborns associate with maternal prenatal stress exposure and newborn birth weight. Epigenetics 853-857.

Murray, L., Fearon, P., Cooper, P., 2015. Postnatal Depression , Mother - Infant Interactions , and Child Development Prospects for Screening and Treatment. Identifying Perinat. Depress. Anxiety EvidenceBased Pract. Screening, Psychosoc. Assessment, Manag.

Nakajima, A., Vogelzang, A., Maruya, M., Miyajima, M., Murata, M., Son, A., Kuwahara, T., Tsuruyama, T., Yamada, S., Matsuura, M., Nakase, H., Peterson, D.A., Fagarasan, S., Suzuki, K., 2018. IgA regulates the composition and metabolic function of gut microbiota by promoting symbiosis between bacteria. J. Exp. Med. 215, 2019-2034. https://doi.org/10.1084/jem.20180427

Neville, M.C., Keller, R., Seacat, J., Lutes, V., Neifert, M., Casey, C., Allen, J., Archer, P., 1988. Studies in human lactation: Milk volumes in lactating women during the onset of lactation and full lactation. Am. J. Clin. Nutr. https://doi.org/10.1093/ajcn/48.6.1375

Neville, M.C., Morton, J., 2018. Symposium : Human Lactogenesis II : Mechanisms , Determinants and Consequences Physiology and Endocrine Changes Underlying Human Lactogenesis II 1 , 2 3005-3008.

O’Connor, M.E., Schmidt, W., Carroll-Pankhurst, C., Onless, K.N., 1998. Relaxation Training and Breast Milk Secretory IgA 152, 1065-1070.

Örün, E., Songül Yalçin, S., Aykut, O., Orhan, G., Koç-Morgil, G., Yurdakök, K., Uzun, R., 2012. Mercury exposure via breast-milk in infants from a suburban area of Ankara, Turkey. Turk. J. Pediatr. 54, 136143.

Ozbek, A., Kumral, A., Guvenir, T., Tas, F.V., Gencer, O., Duman, N., Ozkan, H., 2008. Maternal 
psychosocial aspects in hypernatremic dehydration with high sodium concentrations in breast milk: A case-control study. J. Paediatr. Child Health 44, 38-43. https://doi.org/10.1111/j.14401754.2007.01208.x

Palmeira, P., Carneiro-Sampaio, M., 2016. Immunology of breast milk. Rev. Assoc. Med. Bras. 62, 584-593.

Pang, W.W., Hartmann, P.E., 2007. Initiation of human lactation: Secretory differentiation and secretory activation. J. Mammary Gland Biol. Neoplasia. https://doi.org/10.1007/s10911-007-9054-4

Parry, B.L., Meliska, C.J., Ph, D., Sorenson, D.L., Lopez, A.M., Martinez, L.F., Nowakowski, S., Elliott, J.A., Ph, D., Hauger, R.L., Kripke, D.F., 2008. Plasma Melatonin Circadian Rhythm Disturbances During Pregnancy and Postpartum in Depressed Women and Women With Personal or Family Histories of Depression 1551-1558.

Paschetta, E., Berrisford, G., Coccia, F., Whitmore, J., Wood, A.G., Pretlove, S., Ismail, K.M.K., 2014. Perinatal psychiatric disorders: An overview. Am. J. Obstet. Gynecol. 210, 501-509.e6. https://doi.org/10.1016/j.ajog.2013.10.009

Pauline M. Emmett, I.S.R., Emmett, P.M., Rogers, I.S., Pauline M. Emmett, I.S.R., 1997. Properties of human milk and their relationship with maternal nutrition. Rogers I Early Hum. Dev. https://doi.org/10.1016/S0378-3782(97)00051-0

Pearlstein, T., Howard, M., Salisbury, A., Zlotnick, C., 2009. Postpartum depression. Nih 200, 357-364. https://doi.org/10.1016/j.ajog.2008.11.033.Postpartum

Picciano, M.F., 2001. Nutrient composition of human milk. Pediatr. Clin. North Am. 48, 53-67. https://doi.org/10.1016/S0031-3955(05)70285-6

Prentice, A., Ewing, G., Roberts, S.B., Lucas, A., MacCARTHY, A., A Jarjou, L.M., Whitehead, R.G., Prentice, A., 1987. The Nutritional Role of Breast-Milk IgA and Lactoferrin. Acta Pcediatr Scand. https://doi.org/10.1111/j.1651-2227.1987.tb10526.x

Pribylova, J., Krausova, K., Kocourkova, I., Rossmann, P., Klimesova, K., Kverka, M., TlaskalovaHogenova, H., 2012. Colostrum of healthy mothers contains broad spectrum of secretory $\operatorname{IgA}$ autoantibodies. J. Clin. Immunol. 32, 1372-1380. https://doi.org/10.1007/s10875-012-9733-9

Qawasmi, A., Landeros-Weisenberger, A., Leckman, J.F., Bloch, M.H., Landeros-Weisenberg, A., Leckman, 
J.F., Bloch, M.H., Landeros-Weisenberger, A., Leckman, J.F., Bloch, M.H., 2012. Meta-analysis of Long-Chain Polyunsaturated Fatty Acid Supplementation of Formula and Infant Cognition. Pediatrics 129, 1141-1149. https://doi.org/10.1542/peds.2011-2127

Quigley, M.A., Hockley, C., Carson, C., Kelly, Y., Renfrew, M.J., Sacker, A., 2012. Breastfeeding is associated with improved child cognitive development: A population-based cohort study. J. Pediatr. 160, 25-32. https://doi.org/10.1016/j.jpeds.2011.06.035

Reck, C., Struben, K., Backenstrass, M., Stefenelli, U., Reinig, K., Fuchs, T., Sohn, C., Mundt, C., 2008. Prevalence, onset and comorbidity of postpartum anxiety and depressive disorders. Acta Psychiatr. Scand. 118, 459-468. https://doi.org/10.1111/j.1600-0447.2008.01264.x

Reynolds, R.M., 2013. Glucocorticoid excess and the developmental origins of disease : Two decades of testing the hypothesis - 2012 Curt Richter Award Winner. Psychoneuroendocrinology 38, 1-11. https://doi.org/10.1016/j.psyneuen.2012.08.012

Roux, M.E., Mcwilliams, M., Phillips-quagliata, J.M., Carrington, P.W., Lamm, M.E., 1977. Origin Of IgAsecreting Plasma Cells In The Mammary Gland* 146, 1311-1322.

Saarela, T., Kokkonen, J., Koivisto, M., 2005. Macronutrient and energy contents of human milk fractions during the first six months of lactation. Acta Paediatr. Int. J. Paediatr. 94, 1176-1181. https://doi.org/10.1080/08035250510036499

Sawyer, K.M., Zunszain, P.A., Dazzan, P., Pariante, C.M., 2018. Intergenerational transmission of depression : clinical observations and molecular mechanisms. Mol. Psychiatry. https://doi.org/10.1038/s41380-018-0265-4

Serim Demirgoren, B., Ozbek, A., Ormen, M., Kavurma, C., Ozer, E., Aydın, A., 2017. Do mothers with high sodium levels in their breast milk have high depression and anxiety scores? J. Int. Med. Res. 45, 843-848. https://doi.org/10.1177/0300060517700013

Shariat, M., Abedinia, N., Rezaei, N., Farrokhzad, N., 2017. Increase concentration of transforming growth factor beta (TGF- $\beta$ ) in breast milk of mothers with psychological disorders. Acta Med. Iran. 55, 429436.

Silberg, J., Rutter, M., 2002. Nature-nurture interplay in the risks associated with parental depression., in: 
Children of Depression Parents Mechanims of Risk and Implication of Treatment. pp. 13-36. https://doi.org/10.1037/10449-001

Sinclair, L., Winterborn, M.H., Brown, J., 1968. Smith-Lemli-Opitz Syndrome 907-908.

Sonino, N., Navarrini, C., Ruini, C., Fallo, F., Boscaro, M., Fava, G.A., 2004. Life events in the pathogenesis of hyperprolactinemia $61-65$.

Stein, A., Pearson, R.M., Goodman, S.H., Rapa, E., Rahman, A., McCallum, M., Howard, L.M., Pariante, C.M., 2014. Effects of perinatal mental disorders on the fetus and child. Lancet 384, 1800-1819. https://doi.org/10.1016/S0140-6736(14)61277-0

Sun, M., Zhu, Y., Zhou, Z., Jia, X., Xu, Y., Yang, Q., Cui, C., Shen, Y., 2018. Neuroprotective effects of fecal microbiota transplantation on MPTP-induced Parkinson's s disease mice : Gut microbiota, glial reaction and TLR4 / TNF- a signaling pathway 70, 48-60. https://doi.org/10.1016/j.bbi.2018.02.005

Taveras, E.M., Capra, A.M., Braveman, P.A., Jensvold, N.G., Escobar, G.J., Lieu, T.A., Objective, A., 2003. Clinician Support and Psychosocial Risk Factors Associated With Breastfeeding Discontinuation. Pediatrics 112.

Thibeau, S., D’Apolito, K., Minnick, A.F., Dietrich, M.S., Kane, B., Cooley, S., Groer, M., 2016. Relationships of Maternal Stress with Milk Immune Components in African American Mothers of Healthy Term Infants. Breastfeed. Med. 11, 6-14. https://doi.org/10.1089/bfm.2015.0117

Thomas, R.M., Kawamoto, J., Sneed, S.M., Eakin, R., 1979. The effects of vitamin C, vitamin B6 and vitamin B12, supplementation on the breast milk and maternal status of well-nourished women. Am. J. Clin. Nutr.

Thompson, O., Ajayi, I.O., 2016. Prevalence of Antenatal Depression and Associated Risk Factors among Pregnant Women Attending Antenatal Clinics in Abeokuta North Local Government Area, Nigeria. Depress. Res. Treat. https://doi.org/10.1155/2016/4518979

Vaiserman, A.M., 2015. Epigenetic programming by early-life stress: Evidence from human populations. Dev. Dyn. 244, 254-265. https://doi.org/10.1002/dvdy.24211

Valentine, C.J., Wagner, C.L., 2013. Nutritional Management of the Breastfeeding Dyad. Pediatr. Clin. North Am. 60, 261-274. https://doi.org/10.1016/j.pcl.2012.10.008 
van der Voorn, B., de Waard, M., van Goudoever, J.B., Rotteveel, J., Heijboer, A.C., Finken, M.J., 2016. Breast-Milk Cortisol and Cortisone Concentrations Follow the Diurnal Rhythm of Maternal Hypothalamus-Pituitary-Adrenal Axis Activity. J. Nutr. 146, 2174-2179. https://doi.org/10.3945/jn.116.236349

Westerberg, A.C., Schei, R., Henriksen, C., Smith, L., Veier??d, M.B., Drevon, C.A., Iversen, P.O., 2011. Attention among very low birth weight infants following early supplementation with docosahexaenoic and arachidonic acid. Acta Paediatr. Int. J. Paediatr. 100, 47-52. https://doi.org/10.1111/j.16512227.2010.01946.x

Zanardo, V., Nicolussi, S., Favaro, F., Faggian, D., Plebani, M., Marzari, F., Freato, F., 2001. Effect of postpartum anxiety on the colostral milk $\beta$-endorphin concentrations of breastfeeding mothers. $\mathrm{J}$. Obstet. Gynaecol. (Lahore). https://doi.org/10.1080/01443610020026001

Zunszain, P.A., Anacker, C., Cattaneo, A., Choudhury, S., Musaelyan, K., Myint, A.M., Thuret, S., Price, J., Pariante, C.M., 2012. Interleukin-1 $\beta$ : A new regulator of the kynurenine pathway affecting human hippocampal neurogenesis. Neuropsychopharmacology 37, 939-949.

https://doi.org/10.1038/npp.2011.277 